\section{Summary of: School bullying and traumatic dental injuries in East London adolescents}

\author{
M. Agel, ${ }^{1}$ W. Marcenes ${ }^{2}$ and E. Bernabé*1
}

\begin{tabular}{l} 
FULL PAPER DETAILS \\
\hline${ }^{1}$ King's College London Dental Institute at Guy's, \\
King's College and St. Thomas' Hospitals, Division \\
of Population and Patient Health, London, United \\
Kingdom; 'Institute of Dentistry, Barts and The \\
London School of Medicine and Dentistry, Queen Mary \\
University of London, London, United Kingdom \\
${ }^{*}$ Correspondence to: Dr Eduardo Bernabé \\
Email: eduardo.bernabe@ @ kcl.ac.uk \\
Tel: +44 (0)203 2993022 \\
Online article number E26 \\
Refereed Paper - accepted 24 October 2014 \\
DOI: $10.1038 / s j . b d j .2014 .1123$ \\
'British Dental Journal 2014; 217: E26
\end{tabular}

\begin{abstract}
Aim To explore the association between school bullying and traumatic dental injuries (TDI) among 15-16-year-old school children from East London. Design Data from phase III of the Research with East London Adolescents Community Health Survey (RELACHS), a school-based prospective study of a representative sample of adolescents, were analysed. Adolescents provided information on demographic characteristics, socioeconomic measures and frequency of bullying in school through self-administered questionnaires and were clinically examined for overjet, lip coverage and TDI. The association between school bullying and TDI was assessed using binary logistic regression models. Results The prevalence of TDI was 17\%, while lifetime and current prevalence of bullying was 32\% and 11\%, respectively. The prevalence of TDI increased with a growing frequency of bullying; from 16\% among adolescents who had never been bullied at school, to $21 \%$ among those who were bullied in the past but not this school term, to $22 \%$ for those who were bullied this school term. However, this association was not statistically significant either in crude or adjusted regression models. Conclusion There was no evidence of an association between frequency of school bullying and TDI in this sample of 15-16-year-old adolescents in East London.
\end{abstract}

\section{EDITOR'S SUMMARY}

Accidents happen. That is a fact of life. However, all the health and safety procedures in the world (and in my experience there is certainly no shortage of these!) won't stop someone from intentionally hurting someone else. They won't stop a child purposefully causing a classmate to damage a tooth by hitting them or pushing them over in the playground. Thus it's important to explore what is behind the 'accidents' that cause injuries to children to determine if there is a particular cause which needs to be addressed.

The authors of this $B D J$ paper started to investigate one possible reason for the 'accidents' causing children to suffer from traumatic dental injuries (TDI) at school - bullying. Dental trauma at school is a relatively frequent event. The prevalance of TDI was found to be $17 \%$ for the cohort of 15-16-year-old school children in three East London boroughs surveyed in this study. Indeed, a new charity, Dental Trauma UK, has recently been set up with an objective to raise awareness among the general public about what to do in cases of traumatic injuries to teeth. It is particularly aimed at teachers as they are on the frontline. ${ }^{1}$
Previous studies have shown that bullying in the UK is also prevalent - 26\% of children aged 8-9 reported being bullied. In this study lifetime bullying of the cohort was reported as $32 \%$. Past research studies and good old experience intimate that there could be a connection between TDI and school bullying. This is the first study to actually explore the possible association between bullying and TDI in school-aged children.

The result was a negative one ie no association was determined. The authors propose a number of reasons as to why this might be the case, namely sample size, sample age group (possibly too old) and information collection. They also acknowledge that there might not be a true association between bullying and TDI. However, the authors do caution against stopping this direction of research on the basis of this single result, rather they see it as a starting point for further research looking specifically at links between bullying and TDI. This paper will get more people thinking about study designs and possible research methods which should hopefully result in a more conclusive answer on whether or not such an association actually exists.
The full paper can be accessed from the $B D J$ website (www.bdj.co.uk), under 'Research' in the table of contents for Volume 217 issue 12.

Ruth Doherty Managing Editor DOI: 10.1038/sj.bdj.2014.1124

1. K. Quinlan. New charity will educate on dental trauma. News article. Br Dent J 2014; 217: 331. 


\section{TO ACCESS THE BDJ WEBSITE TO READ THE FULL PAPER}

- BDA Members should go to www.bda.org.

- Click the 'login' button on the right-hand side and enter your BDA login details.

- Once you have logged in click the 'BDJ' tab to transfer to the BDJ website with full access.

IF YOUR LOGIN DETAILS DO NOT WORK:

- Get a password reminder: go to www.bda.org, click the login button on the right-hand side and then click the forgotten password link.

- Use a recommended browser: we recommend Microsoft Internet Explorer or Mozilla Firefox.

- Ensure that the security settings on your browser are set to recommended levels.

IF YOU HAVE NOT YET SIGNED UP TO USE THE BDA WEBSITE:

- Go to www.bda.org/getstarted for information on how to start using the BDA website.

\section{COMMENTARY}

Agel et al.'s paper set out to examine the association between bullying and traumatic dental injuries in adolescence. At first glance the findings appear disappointing, since the authors were unable to demonstrate a statistically significant association between experience of bullying and traumatic dental injury, however, to adopt this position is to ignore the important implications this work has for the prevention of bullying, associated injuries and the ultimate promotion of prosocial behaviour. ${ }^{1}$ The reader must, therefore, return to the paper and carefully examine the results since this will permit an exploration of the underlying influences of psychological development, ethnicity and parental socio-economic position. These three elements may be conceptualised as ethnocentrism, and it is proposed that it is ethnocentrism that affects the prevalence of bullying in preadolescence and adolescence proper. ${ }^{2,3}$

In essence ethnocentrism reflects the role of group membership in terms of group culture, affiliation and identity. ${ }^{1}$ It is how one group's rivalry and hostility are foisted upon those in another group that is at the centre of the extreme behaviours that give rise to the bullying actions, characteristic of adolescence. Thus, this work, provides a platform to explore how an understanding of these elements could be used to counter the 'Cruel and bullying actions [that] are regular occurrences' in adolescence. ${ }^{2}$ Such an awareness starts the process and paves the way to build strategies to reduce bullying and associated injuries.

To support the above proposition, the reader is pointed to the authors' findings. In their sample of 15-16-year-old adolescents, the authors show that the experi- ence of bullying decreased with age but persisted in male rather than female participants; persistent bullying was more prevalent in White and mixed ethnic group adolescents and persistent bullying was connected to adolescent experience of traumatic dental injuries. This collection of results supports the view that the persistence of 'cruel and bullying actions' ${ }^{2}$ was associated with older, male adolescents and imposed upon adolescents from, for example, other ethnic groups and/or those whose parents were unemployed. The results, of such cruel behaviours, are to be found in the physical and psycho-social sequelae of those bullied throughout their adolescence.

To enable adolescents 'to live together', strategies to recognise and contain persistent bullying must be considered. Doing so will allow all those involved in the care of adolescents, whether in dental public health or primary dental care settings, to recognise that traumatic dental injuries, in late adolescence, may be a sign of persistent bullying. This will, in turn, allow a series of events, to be set in place that will permit the fostering of prosocial behaviour. The promotion of prosocial behaviour will allow the bullying adolescent of the present to become the empathetic and problem-solving adult of tomorrow. Agel et al.'s work has allowed this process to begin.

1. Hamburg D A, Hamburg B A. Learning to live together. Oxford: Oxford University Press, 2004

2. Freud A. On certain difficulties in the preadolescent's relation to his parents. In Ekins $R$, Freeman R (eds) Selected Writings Anna Freud. pp 165-174. London: Penguin Books, 1998.

3. Freud A. Adolescence. In Ekins R, Freeman R (eds) Selected Writings Anna Freud. pp 175-197. London: Penguin Books, 1998.

Ruth Freeman

Co-Director Dental Health Services Unit, University of Dundee

\section{IN BRIEF}

- Summarises the literature on the possible link between school bullying and dental trauma.

- Discusses possible explanations for the lack of association between school bullying and dental trauma found in the present study.

- Highlights areas for further research that will help clarify the effect of school bullying on dental trauma.

\section{AUTHOR OUESTIONS AND ANSWERS}

1. Why did you undertake this research?

In attempting to prevent or reduce the burden of traumatic dental injuries (TDI), it is important to understand and explore all of the risk factors. Most literature on risk factors indicates that falls and collisions account for most injuries seen. However, the broad categories of falls and collisions may mask the true underlying causes of dental trauma, such as intentional acts of violence, bullying or abuse, because they do not assess intention. A more thorough investigation into the circumstances leading to the incident is arguably needed. Although a possible link between bullying and TDI has been speculated in the literature, no formal assessment has been conducted yet. Provided that a connection between bullying and traumatic dental injuries exist, prevention strategies to deal with traumatic dental injuries in schools could include firmer policies to deal with any behaviour that results in physical harm to victims.

\section{What would you like to do next in this} area to follow on from this work? This was the first attempt to explore the association between school bullying and TDI. Although a link between the two conditions was not found in this study, further work on this topic would be required before an association is completely ruled out. Longitudinal data would provide a stringent control over the temporal sequence between bullying experience and dental trauma occurrence and provide a stringent evaluation of a causal relationship. It would also be advantageous to recruit children at younger ages where bullying is more frequently reported. A focus on physical bullying is also important as other forms of bullying (such as verbal, relational or cyber bullying) may not be directly connected to the experience of dental trauma. 